\title{
Social positioning correlates with consensus building in two contentious large-group meetings
}

\author{
David T. Brookes \\ Department of Physics, California State University, Chico, 400 W. 1st St., Chico, CA 95929-0202 \\ Brant E. Hinrichs and Jacob L. Nass \\ Department of Physics, Drury University, 729 N. Drury Lane, Springfield, MO 65802
}

\begin{abstract}
This paper analyzes two examples of whiteboard meetings from a college calculus-based introductory physics course taught using University Modeling Instruction. In this pedagogy, students work in small groups to create a solution to the same problem on $2^{\prime} \times 3^{\prime}$ whiteboards. They then sit in a large circle with their whiteboards held facing in and conduct a student-led whole-class discussion ("board" meeting) to reach a consensus. One example is given of a conversation where students overcame sharp disagreements to eventually reach whole-class consensus and another example is given where they did not. We examine how social positioning contributed to students either successfully examining and resolving different ideas or failing to do so. Initial results from two different "board" meetings tentatively support the idea that meetings where "experts" soften their position by "hedging" more frequently are better able to overcome sharp initial disagreements to reach consensus on their own. Our analysis suggests that the way students position themselves in discussions may open or close the collaborative space to productive sense-making.
\end{abstract}

2019 PERC Proceedings edited by Cao, Wolf, and Bennett; Peer-reviewed, doi.org/10.1119/perc.2019.pr.Brookes

Published by the American Association of Physics Teachers under a Creative Commons Attribution 4.0 license.

Further distribution must maintain attribution to the article's authors, cover page, and DOI. 


\section{INTRODUCTION}

The heart of University Modeling Instruction [1-5] is Modeling Discourse Management (MDM) [6], a learningcommunity approach that explicitly focuses on the epistemology of science. It is designed to help students understand that the conclusions of science are tentative and evolving and that knowledge and understanding of meaning are constructed and shared through dialogue with others. In MDM, students work in small groups to create a solution to the same problem on a $2^{\prime} \times 3^{\prime}$ whiteboard. They then sit in a large circle with their whiteboards held facing in and conduct a student-led wholeclass discussion ("board" meeting) to reach consensus [7].

In our experience, groups in a class sometimes come into a board meeting with very different answers to the same prompt. Often those meetings resolve relatively easily, but occasionally they do not. We call these latter occurrences contentious board meetings. We have observed that in some contentious board meetings the class is still able to come to a consensus, overcoming their sharp initial disagreements without the intervention of the instructor [7], but in other cases they fail to do so. Our research question was to understand why.

We present our results from coding and analyzing two different contentious board meetings from an introductory calculus-based physics course taught by one of the authors. One meeting successfully reached consensus on its own, while the other did not. Looking at these students' discussions through a participationist lens [8], we compare and contrast the dynamics of social positioning for the two. We have refined and used a coding scheme that was developed previously [9], which now identifies five social positioning "moves" students use in conversation with each other.

As identified by our coding scheme, we found that the two meetings had similar features in their "presentation" and "early discussion" phases. But in the "later discussion" phase, the board meeting that reached resolution had key features that set it apart from the contrasting board meeting where resolution was not reached. These features include group "experts" frequently softening their position by means of "hedging", use of humor to relieve the tension at critical junctures, and pivotal facilitation moves. Our tentative conclusion is that students in the more successful board meeting used a number of key techniques that opened up the space for collaboration and sense-making.

\section{THEORY-SOCIAL POSITIONING}

In order to understand the social dynamics of classroom discussions and how these dynamics might impact how students successfully construct normative physics knowledge, we examine the classroom through a participationist lens [8]. In this view, students are participants in a community of practice [10], where they participate with varying degrees of centrality depending on their status in the community. This idea has been modified and extended so that we now understand that students can dynamically position themselves in a conversation thus creating a transient positional identity $[11,12]$. Research suggests that these positional identities and the bids or moves that people make to establish them can open up or close down the collaborative space to productive sensemaking [9, 11, 13].

Prior research and preliminary work of ours [9] suggest that students who make hedged statements to soften their position open up the space for collaboration and sense-making. A hedge is a phrase that can "soften" a statement. So instead of making a direct statement like "the answer is forty-two," a student might preface the same statement with a hedge like "maybe" ("Maybe the answer is forty-two."). Fragale [14] showed that when groups of people are asked to collaborate to solve a problem, group members who made hedged statements achieved higher status and recognition when the task is more "interdependent" whereas the "powerful" speakers (members who make emphatic or unhedged statements) were accorded higher status when the activity had lower task interdependence. Task interdependence is defined as the degree to which group members need to collaborate, coordinate or interact in order to complete the assigned task [15]. Conlin and Scherr have shown that in addition to hedging, students also create epistemic distance (thereby opening the space to sense-making) through humor and by rephrasing a statement as a question [13].

Based on these ideas, we have refined a previously developed coding scheme [9], to identify students' positional moves during a conversation. The coding scheme is explained in Section III B.

\section{METHODOLOGY}

\section{A. The two board meetings}

We coded two contentious board meetings: one that achieved consensus on its own and one that did not. As mentioned in the introduction, contentious board meetings are rare, and those that resolve on their own are even rarer. We selected the first two episodes we encountered that fit our criteria. Both board meetings involved activities that were highly task interdependent [15] for reasons elaborated below. In the first meeting, students worked on a problem called "A Quick Little Problem" (QLP): "You walk into a room and see a book sliding across the floor and slowing down. The book then comes to rest. You did not see what caused the book to start moving in the first place and do not care." Among other things, students are asked to make a system schema [16] and force diagram for the book. This was their first encounter with (i) friction in the context of forces, and (ii) angled forces. The board meeting for this was late in the first semester of the introductory calculus-based physics course at Drury University, Fall 2011 [7]. The key point of contention in this problem was whether to include friction as part of the contact interaction between the surface and the block or not. In the second meeting, students worked on a problem called 
“Two Stacked Blocks" (2SB). It is a goal-less problem [17] in which students are shown the diagram in Fig. 1 and asked to find everything that they possibly can. This is their first encounter with objects with mass that interact vertically. The board meeting was contentious because the class struggled with accounting for how the mass of block B affected block A and how to model both blocks to allow for B to eventually slide off $\mathrm{A}$. This meeting occurred early in the second semester of an introductory calculus-based physics course at Drury, Spring 2017 [18].

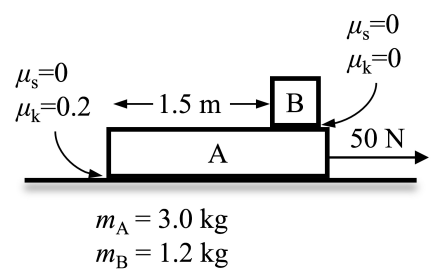

FIG. 1. Diagram students are given for the two stacked blocks problem (2SB).

\section{B. The coding scheme}

The refined coding scheme retains five positional moves from the original framework [9]. A student who positions themselves as an "expert" providing an idea or answering a question can do so in a "firm" manner or "softened" manner, using hedges. In a similar way, a student who assumes a "novice" position can ask a probing question that potentially contributes to driving the conversation forward, or can ask a question or make a statement that suggests some degree of "I am helpless and confused/I have no idea/please help me." Lastly, a student can make comments that have little direct conceptual content, yet support the discussion in a productive manner. Table I describes and gives an example of each positional move.

Audio recordings of the two meetings were transcribed verbatim and the transcript was separated into 15 second intervals. The coding scheme was applied as follows: If a student only made firm statements in the interval they were coded 1. If in addition to firm statements they also made any hedge in that 15 second interval, they were coded 2 instead. If a student made firm statements and asked a question in an interval they were coded 2 . If a student only asked questions in an interval they were coded 3 or 4 by the criteria above. If a student only made a facilitation move in the 15 second interval they were coded 5 , otherwise the facilitation was ignored.

\section{Coding and inter-rater reliability}

We started by coding the 40 minute 2 Stacked Blocks transcript in 10 minute chunks as the second author learned the coding scheme from the first author. The first chunk, minutes $0-10$, was coded collaboratively. Then we separated and did
TABLE I. Descriptions and examples of each positional move in our coding scheme.

\begin{tabular}{|c|c|c|}
\hline $\begin{array}{l}\text { Positional } \\
\text { move (code } \\
\#)\end{array}$ & Description & Examples \\
\hline Expert (1) & $\begin{array}{l}\text { Firm statements of } \\
\text { fact or firm/strong } \\
\text { disagreement }\end{array}$ & $\begin{array}{l}\text { Dave: "... when we get to the } \\
\text { force diagrams, ours is at an an- } \\
\text { gle, um, we did that because } \\
\text { like we went through the mo- } \\
\text { tion diagram up here and we de- } \\
\text { termined our acceleration had } \\
\text { to be pointing in the negative } \\
\text { direction." }\end{array}$ \\
\hline $\begin{array}{l}\text { Intermediate } \\
\text { expert (2) }\end{array}$ & $\begin{array}{l}\text { Softened state- } \\
\text { ments or softened } \\
\text { disagreement, } \\
\text { using hedges or } \\
\text { upward inflection } \\
\text { at the end of a } \\
\text { sentence. }\end{array}$ & $\begin{array}{l}\text { Min: "Ok, well, we had es- } \\
\text { sentially the same thing, except } \\
\text { we labeled our other interaction } \\
\text { the unknown interaction, but I } \\
\text { guess we could have labeled it } \\
\text { friction, that would have been } \\
\text { smart." (Hedges highlighted in } \\
\text { italics.) }\end{array}$ \\
\hline $\begin{array}{l}\text { Intermediate } \\
\text { novice (3) }\end{array}$ & $\begin{array}{l}\text { Questions that drive } \\
\text { the conversation. }\end{array}$ & $\begin{array}{l}\text { Kim: "I just wanna know why } \\
\text { you can... say there's a vector } \\
\text { for friction if it's not an inter- } \\
\text { action within your schema?" }\end{array}$ \\
\hline Novice (4) & $\begin{array}{l}\text { Questions or state- } \\
\text { ments that convey } \\
\text { helplessness or } \\
\text { confusion. }\end{array}$ & $\begin{array}{l}\text { Chad: "... when we got to } \\
\text { the force diagram, we kind of, } \\
\text { threw our hands up, and said } \\
\text { well, hopefully you guys will } \\
\text { teach us." }\end{array}$ \\
\hline $\begin{array}{l}\text { Facilitator } \\
\text { (5) }\end{array}$ & $\begin{array}{l}\text { Meta-level state- } \\
\text { ments or questions } \\
\text { that facilitate the } \\
\text { discussion in some } \\
\text { way. }\end{array}$ & $\begin{array}{l}\text { Sue: "With that being said, I do } \\
\text { agree with your board, and your } \\
\text { board, so respect your stuff." }\end{array}$ \\
\hline
\end{tabular}

the next 10 minute chunk on our own before comparing again, using Cohen's Kappa to assess our agreement. We repeated that process for the last two chunks of 2SB. After 2SB, we coded QLP in one go and compared. Our level of agreement is shown in Table II:

TABLE II. Inter-rater agreement as measured by Cohen's Kappa. Inter-rater agreement reached between $\kappa=0.96 \& \kappa=1$ after discussion.

\begin{tabular}{cccr}
\hline \hline & 2 Stacked Blocks & & QLP \\
10:00-20:00 & $20: 00-30: 00$ & $30: 00-42: 00$ & $0: 00-16: 00$ \\
\hline$\kappa=0.62^{\mathrm{a}}$ & $\kappa=0.68^{\mathrm{a}}$ & $\kappa=0.67^{\mathrm{a}}$ & $\kappa=0.76^{\mathrm{a}}$ \\
\hline \hline
\end{tabular}

${ }^{a} \kappa$ between 0.6 and 0.8 indicate a "substantial" level of agreement [19]

\section{RESULTS AND ANALYSIS}

In these two board meetings, students went through a natural flow (Table III) that began with shuffling around and or- 
ganizing seating, then each group had a group representative presenting their whiteboard to the rest of the class. Once all the groups had presented, the meeting naturally transitioned to discussion which continued until resolution was reached or the students gave up.

TABLE III. Timeline for both board meetings.

\begin{tabular}{ccccc}
\hline \hline & \multicolumn{2}{c}{ Quick Little Problem } & \multicolumn{2}{c}{ 2 Stacked Blocks } \\
& Time (s) & $\%$ of total time & Time (s) & \% of total time \\
\hline shuffling & 75 & $7 \%$ & 90 & $4 \%$ \\
presenting & 375 & $36 \%$ & 885 & $35 \%$ \\
discussing & 585 & $57 \%$ & 1545 & $61 \%$ \\
\hline Totals & 1035 & $100 \%$ & 2520 & $100 \%$ \\
\hline \hline
\end{tabular}

We note that 2 SB took substantially longer, probably reflecting the open-endedness of the problem and the fact that it required some challenging object modeling and a more detailed analysis. What is remarkable is how similarly the time is distributed between presenting and discussing when comparing the two meetings.

Figures 2 and 3 present our consensus coding of the two meetings. Each numbered square represents a code assigned to an individual speaker in a 15 -second time interval. The top line represents the overall time in minutes. Overlapping codes in a single interval are ordered numerically with 1 at the top and 5 at the bottom.

From our data, we observe three distinct phases common to both meetings. During the presentation phase (minutes $1-7$ in Fig. 2, minutes 1-16 in Fig. 3), the conversation took the form of a presentation that was dominated by unhedged statements with occasional deviations from presenters who took a more tentative position. This was followed by an early discussion phase (minutes 8-11 in Fig. 2; minutes 17-29 in Fig. 3). This period involved several voices contributing to each 15 -second interval, some emphatic (coded 1) and some hedged (coded 2). The positioning was characterized by frequent jumping back and forth between sections with more 1 statements and then sections with more 2 statements as well as occasional questions (code 3) and facilitation moves (code 5). During these two phases, QLP and 2SB were remarkably similar.

The two meetings are, however, clearly distinguished in the third phase which we call "later discussion" (minutes 12-15 in Fig. 2, minutes 30-41 in Fig. 3). The later discussion in QLP was dominated by hedged statements (coded 2). These were specific statements in which participants offered a resolution to their conundrum (is friction a component of the surface interaction or a separate force?), but in a hedged manner, leading to this idea being taken up by the whole class. For example:

Sam: “Isn't friction, like, due to contact? It's, it's a product of it ... So is it, is it possible to label it is as its own interaction or is it due to the contact interaction? It's a product.

In contrast, $2 \mathrm{SB}$ in the same period is characterized by more unhedged statements as compared to QLP. These statements also appear to take the form of "talking past" each other, leading to frustration and unresolved disagreement. The following prickly exchange between John and Wilson epitomizes that:

John: "And then we said there's friction between
box A and the ground, which is a part of
the frictional coefficient, like for mu."
Wilson: "We don't need to assume that, it is part of
the problem."
John: "Well then you wouldn't need to say the
other one if it's just part of the problem."
Wilson: "This isn't an assumption, this is a fact."

\section{DISCUSSION}

We hypothesize that one key feature of the QLP discussion that separated it from the $2 \mathrm{SB}$ discussion was the way in which the resolution to the contentious issue (is friction part of the contact interaction?) was presented: namely with hedges. This is consistent with Fragale's findings, that people who make hedged statements are accorded higher status in scenarios of high task interdependence. We also see key moments in QLP that seemed to open up the collaborative space in ways similar to what Conlin and Scherr found [13]. In particular, a moment of levity was introduced by Jim who refers to the sliding book as a "book-box" because of an earlier inconsistent phrasing of the problem involving a box rather than a book. The humor was shared by many class members who audibly laughed in response to his dead-pan presentation. We also observed moments of facilitation that seemed critical to the atmosphere of the discussion in QLP and were missing from the 2SB discussion. We already showed one example in Table I where Sue encourages another group to "respect your stuff". In addition, multiple students made attempts to summarize the nature of the contentious issue in a non-confrontational way, for example:

$$
\begin{aligned}
& \text { Sam: "So, basically, the, the major differ- } \\
& \text { ence between... our group consensuses } \\
& \text { are... centered around whether or not fric- } \\
& \text { tion is an interaction." }
\end{aligned}
$$

Both classes came into these board meetings with similar prior experience in UMI and MDM. Neither was at all new to the pedagogy. But it is possible that class demographics were partially responsible for why the QLP group was more successful at resolving differences than the 2SB group. While the 2017 class had an average year in school of 1.88 (4 freshman, 16 sophomores, 2 juniors, 0 seniors), the 2011 class was almost a full year older, with an average year of 2.74 (1 freshman, 11 sophomores, 10 juniors, and 5 seniors). Future research will involve identifying and coding additional contentious board meetings that do and don't achieve consensus to see if the correlations seen in this paper hold up to further scrutiny. 


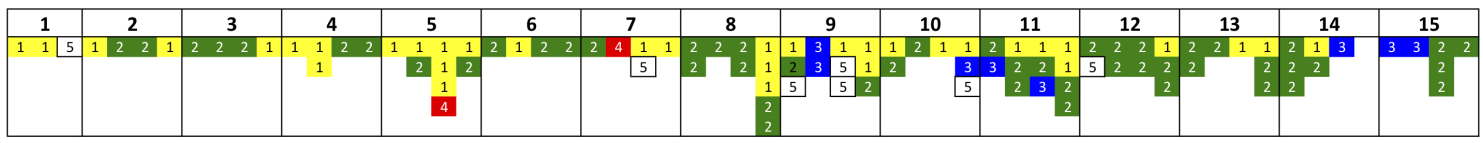

FIG. 2. Quick Little Problem coding: In a class of 26 students, 10 remained silent, and 16 participated in the conversation [7].

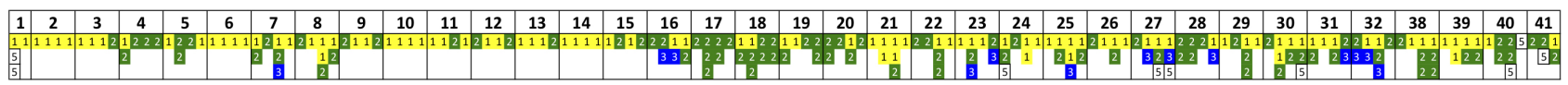

FIG. 3. 2 Stacked Blocks coding. Out of a class of 22 students, 8 remained silent, and 14 participated in the conversation. There was a 5-minute uncodable gap in the transcript when the entire class broke into side conversation before re-convening to continue the whole-class discussion.

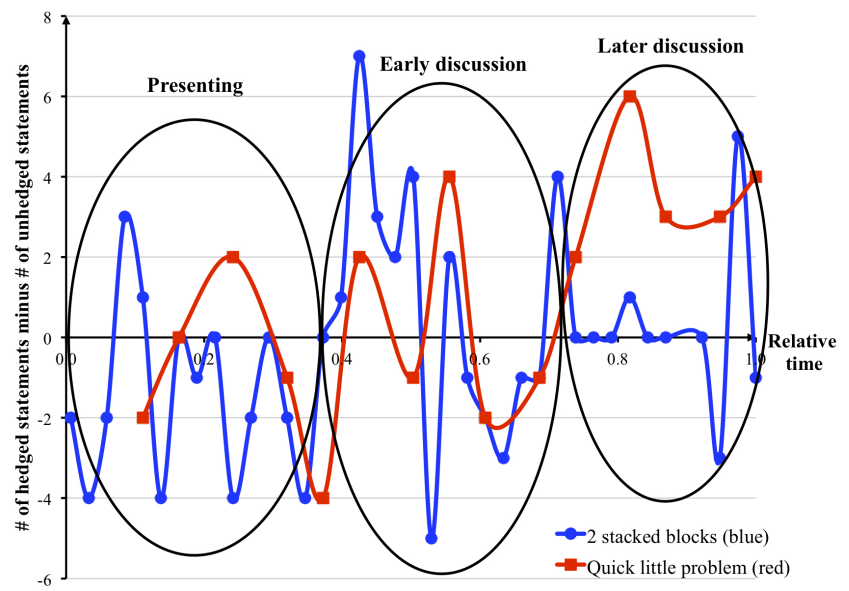

FIG. 4. The difference between hedged and unhedged statements totaled in minute intervals.

In conclusion, we suggest that examining how students position themselves in discussion may be a productive way to understand why some discussions are more successful and productive than others. Further research might involve "coaching" students in ways of expressing their ideas in a way that opens up the discussion rather than closing it down, and examining the effect of this coaching on how subsequent contentious discussions are resolved or not resolved.

\section{ACKNOWLEDGMENTS}

JN thanks Collin Huitt for helpful peer collaboration. BH thanks Miki, Eads, \& Fenn for encouragement \& support, Kristen Kaughman for demographic data, Drury for a sabbatical to work on this project, the Drury Provost's office for a grant to support an undergraduate on this project, IRISE for professional development, Vashti Sawtelle and Benedikt Harrer for their long term interest, encouragement, advice and support, DB for effective mentorhsip and kind hospitality, and the kindness and mercy of God. DB and BH thank PERLOC for a "scholar-in-residence" mini-grant that enabled us to collaborate extremely productively on this research project.
[1] D. Hestenes, Toward a modeling theory of physics instruction, Am. J. Phys. 55, 440 (1987).

[2] M. Wells, D. Hestenes, and G. Swackhamer, A modeling method for high school physics instruction, Am. J. Phys. 63, 606 (1995).

[3] I. A. Halloun, Modeling Theory in Science Education (Springer, Dordrecht, 2006).

[4] E. Brewe, Modeling theory applied: Modeling Instruction in introductory physics, Am. J. Phys. 76, 1155 (2008).

[5] E. Brewe and V. Sawtelle, Modelling instruction for university physics: examining the theory in practice, Eur. J. Phys. 39, 054001 (2018).

[6] D. M. Desbien, Modeling Discourse Management Compared to Other Classroom Management Styles in University Physics, Ph.D. thesis, Arizona State University (2002).

[7] B. E. Hinrichs, Sharp Initial Disagreements Then Consensus in a Student Led Whole-Class Discussion, in Proceedings of the 2013 Physics Education Research Conference, edited by P. V.
Engelhardt, A. D. Churukian, and D. L. Jones (AIP Conference Proceedings, Melville, NY, 2014) pp. 181-184.

[8] A. Sfard, When the rules of discourse change, but nobody tells you: Making sense of mathematics learning from a commognitive standpoint, J. Learn. Sci. 16, 565 (2007).

[9] D. T. Brookes, B. Nainabasti, and Y. Yang, Characterizing Student Participation in an ISLE Physics Class, in Proceedings of the 2013 Physics Education Research Conference, edited by P. V. Engelhardt, A. D. Churukian, and D. L. Jones (AIP Conference Proceedings, Melville, NY, 2014) pp. 77-80.

[10] J. Lave and E. Wenger, Situated Learning: Legitimate Peripheral Participation (Cambridge University Press, Cambridge, U.K., 1991).

[11] I. Esmonde, Ideas and identities: Supporting equity in cooperative mathematics learning, Rev. Educ. Res. 79, 1008 (2009).

[12] N. Bonderup Dohn, Explaining the Significance of Participationist Approaches for Understanding Students' Knowledge Acquisition, Educ. Psychol. 51, 188 (2016). 
[13] L. D. Conlin and R. E. Scherr, Making Space to Sensemake: Epistemic Distancing in Small Group Physics Discussions, Cogn. \& Instr. 36, 396 (2018).

[14] A. R. Fragale, The power of powerless speech: The effects of speech style and task interdependence on status conferral, Organizational Behavior and Human Decision Processes 101, 243 (2006).

[15] R. Wageman, Interdependence and Group Effectiveness, Admin. Sci. Quart. 40, 145 (1995).

[16] B. E. Hinrichs, Using the System Schema Representational Tool to Promote Student Understanding of Newton's Third Law, in Proceedings of the 2004 Physics Education Re- search Conference, Vol. 790, edited by J. Marx, P. Heron, and S. Franklin (American Institute of Physics, Melville, NY, 2005) pp. 117-120.

[17] P. D'Alessandris, The Development of Conceptual Understanding and Problem-Solving Skills through Multiple Representations and Goal-less Problems (1994).

[18] Both problems are used here with permission from Dwain Desbien.

[19] R. J. Landis and G. G. Koch, The Measurement of Observer Agreement for Categorical Data, Biometrics 33, 159 (1977). 